\title{
Kebijakan Kepala Madrasah dalam Meningkatkan Kompetensi Profesional Guru di MI NW Lendang Ara
}

\author{
Abdul Hafiz Alfatoni \& Hamzani Aulia Rahman \\ UIN Sunan Kalijaga Yogyakarta \\ Hafizalfatoni70@gmail.com,Hamzaniauliarahman@gmail.com
}

\begin{abstract}
This research aims to find out how the head of MADRASAH MI NW Lendang Ara made a policy in improving the professional competence of teachers. Policy is the fundamental basis for carrying out something with a specific purpose. This study uses qualitative, namely research conducted descriptively and analyze fe-nomena, events, social activities, attitudes, beliefs and perspectives of each person or group, while the data collection in this study using observations and interviews. This research was conducted at MI NW Lendang Ara, Kec. Kopang Central Lombok. In improving the professional competence of teachers the head of madrasah MI NW Lendang ara makes policies to make teacher training such as holding seminars, supervision, multi-disciplinary training and giving awards for teachers who excel and give freedom to teachers in developing themselves to increase their potential.
\end{abstract}

Keywords: Policy, Head of Madrasah, Competency, Teacher

\begin{abstract}
Abstrak : Penelitian ini bertujuan untuk mengetahui bagaimana kepala madrasah MI NW Lendang Ara membuat kebijakan dalam meningkatkan kompetensi profesional guru. Kebijakan merupakan landasan pokok untuk menjalankan sesuatu dengan tujuan tertentu. Penelitian ini menggunakan kualitatif, yaitu penelitian yang lakukan secara deskriptif serta menganalisis fe-nomena, peristiwa, aktifitas social, sikap, kepercayaan maupun perspektif masing-masing orang maupun kelompok, sedangkan pengumpulan data pada penelitian ini menggunakan da-ta observasi dan wawancara. Penelitian ini dilakukan di MI NW Lendang Ara, Kec. Kopang Lombok Tengah. Dalam meningkatkan kompetensi profesional guru kepala madrasah MI NW Lendang ara membuat kebijakan membuat pelatihan keguruan seperti mengadakan seminar, supervisi, pelatihan multi disiplin keilmuan serta memberikan penghargaan bagi guru yang berprestasi dan memberikan kebebasan kepada guru dalam mengembangkan diri untuk meningkatkan potensi yang mereka miliki.
\end{abstract}

Kata Kunci: Kebijakan, Kepala Madrasah, Kompetensi, Guru 


\section{PENDAHULUAN}

Pendidikan Merupakan Usaha Sadar Yang Dilakukan Secara Sungguh-Sungguh Untuk Mengubah Manusia Agar Menjadi Lebih baik dengan Potensi Yang Ia Miliki. Dalam dunia Pendidikan guru sangat berperan penting dalam menciptakan Pendidikan yang unggul oleh sebab itu dibutuhkan seorang guru yang Profesional dalam bidangnya agar dalam implementasinya sesuai dengan yang diharapkan. Kunandar mengatakan dalam bukunya ciri-ciri guru yang profesional diantaranya. Pertama menguasai bidang keilmuan yang ia geluti. Kedua sudah memenuhi syarat dalam menjalankan profesi yang ia miliki. Ketiga pandai da-lam berkomunikasi terhadap para peserta didik. Keempat kedisiplinan serta ber-tanggung jawab atas profesi yang ia miliki. Kelima selalu mengembangkan diri dalam berbagai hal agar keilmuan yang ia miliki bias terus menerus berembang. ${ }^{2}$

Kepala madrasah memiliki peran penting dalam meningkatkan Profesional guru dengan membuat kebijakan yang sesuai dengan kebutuhan guru maupun peserta didik. $^{3}$ Adapun jenis kebijakan kepala madrasah diantaranya. Pertama kebijakan skala besar artinya kebijakan dari pemerintah pusat namun dikem-bangkan lagi oleh kepala madrasah dalam membuat Pendidikan yang unggul dengan membuat kurikulum yang sesuai dengan kebutuhan. Kedua kebijakan secara khusus yaitu kepala madrasah membuat kebijakan untuk meningkatkan Profesional guru baik itu dengan mengadakan supervisi, membuat seminar maupun pelatihan keguruan lainnya. ${ }^{4}$

Dalam praktiknya jarang sekali kita temukan kebijakan yang bisa meningkatkan profesional seorang guru. Kebijakan yang ada hanya terfokus pada satuan Pendidikan saja. dalam hal ini dari hasil observasi yang dilakukan di MI NW Lendang ara peneliti melihat guru yang ada banyak mengembangkan keilmuannya tidak terputus dalam satu bidang keilmuan saja namun mampu menghubungkan keilmuan yang ia

1 Urip Triyono dan Mufarohah, Bunga Rampai Pendidikan (Formal, Non Formal, dan Informal) (Deepublish, 2018), 1.

2 Kunandar, Guru profesional: implementasi Kurikulum Tingkat Satuan Pendidikan (KTSP) dan persiapan menghadapi sertifikasi guru (Jakarta: RajaGrafindo Persada, 2007), 48.

3 Imron Fauzi, «Problematika Kebijakan Linierisasi Dan Mutasi Guru Di Kabupaten Jember», TARBIYATUNA 12, n. 1 (15 febbraio 2019): 43, https://doi.org/10.36835/tarbiyatuna.v12i1.351.

${ }^{4}$ Ali Jusri Pohan, «Kebijakan Kepala Madrasah Dalam Meningkatkan Profesional Guru», ALMAHYRA (Jurnal Penelitian Dan Pengembangan Keilmuan) 1, n. 02 (31 dicembre 2020): 91. 
miliki dengan keadaan yang ada disekitarnya. ${ }^{5}$ Oleh sebab itu peneliti ingin mengetahui kebijakan apa saja yang dibuat oleh kepala madras-ah MI NW Lendang Ara dalam meningkatkan kompetensi Profesional guru.

\section{Kebijakan Kepala Madrasah}

Kebijakan secara etimologi berasal dari Bahasa Yunani yaitu polis yang diartikan kota. Sedangkan menurut epistimologi kebijakan merupakan suatu gagasan dalam sua-tu Lembaga yang digunakan menjadi sebuah landasan dalam melakukan sesuatu untuk meraih tujuan tertentu. ${ }^{6}$. Adapun dalam kamus besar Bahasa Indonesia kebijakan merupakan sebuah suatu landasan, tujuan, serta sebagai landasan untuk dapat meraih keinginan yang ingin dicapai. ${ }^{7}$

Nanang fattah dalam bukunya ia mengutip pendapat carley mengatakan bahwa ada tiga unsur yang harus ada dalam kebijakan diantaranya. Pertama keputusan yang dikemukakan sebagai landasan dasar untuk melakukan sesuatu. Kedua ketetapan yang dikemukakan dapat diterima oleh akal. Ketiga adanya sistem birokrasi yang dapat mendukung terlaksana suatu kebijakan. ${ }^{8}$

Berbicara mengenai komponen kebijakan diantaranya. Pertama perumusan masalah yaitu dengan adanya perumusan masalah dapat membantu mendapatkan asumsi-asumsi yang tersembunyi, media yang baik, merincikan tujuan-tujuan yang memung-kinkan serta memadukan konsep-konsep yang bertentangan agar mampu menciptakan kebijakan yang baru. Kedua peramalan yaitu dapat menyediakan pengetahuan yang sesuai dengan kebijakan yang berkaitan dengan masalah yang terjadi yang akan da-ting. Ketiga rekomendasi kebijakan yaitu Teknik yang dipakai agar kebijakan yang yang dibuat dapat mencapai tujuan yang diinginkan. Keempat pemantauan yaitu se-buah prosedur dalam menganalisis kebijakan yang digunakan agar mendapatkan in-formasi tentang sebab akibat dari kebijakan tersebut. Kelima

\footnotetext{
${ }^{5}$ Hasil observasi 15 juni 2021.

${ }^{6}$ Sukarman Purba et al., Analisis Kebijakan Pendidikan (Medan: Yayasan Kita Menulis, 2021), 3.

7 Departemen Pendidikan Nasional, Kamus Besar Bahasa Indonesia, Cetakan keempat (Jakarta:

8 Nanang Fattah e Pipih Latifah, Analisis kebijakan pendidikan, cetakan keempat (Bandung: Remaja Rosdakarya, 2014), 135.
} Balai Pustaka, 2007), 149. 
evaluasi yaitu mereview Kembali apakah kebijakan yang dibuat relevan atau tidaknya. ${ }^{9}$

Muhammad ali mengatakan isi yang harus ada dalam kebijakan diantaranya. Per-tama tujuan kebijakan. Kedua rencana atau proposal kebijakan. Ketiga program yang ditawarkan. Keempat terdapat keputusan yang terorganisir. Kelima ada efek yang dihasilkan. ${ }^{10}$

Istilah kepala madrasah merupakan kumpulan dari dua kata yaitu kepala yang bisa berarti ketua, pemimpin dalam suatu Lembaga maupun organisasi. Adapun kata mad-rasah merupakan sebuah Lembaga Pendidikan yang terdapat padanya proses meneri-ma maupun pemberian mata pelajaran. ${ }^{11}$

Dengan definisi tersebut dapat kita artikan bahwa kepala madrasah merupakan pimpinan suatu lembaga Pendidikan yang mempunyai wewenang, memberi arahan maupun kebijakan sebagai landasan serta acuan dalam menjalankan proses pembelaja-ran di madrasah. Dari literatur yang ada dapat kita mengambil kesimpulan bahwa ke-bijakan kepala madrasah merupakan suatu landasan maupun aturan yang ditetapkan oleh kepala madrasah sebagai acuan dalam menjalankan proses pembelajaran untuk meraih keinginan yang ingin dicapai. Dalam menentukan kebijakan kepala madrasah dilandasi oleh undang-undang nomor 14 tahun 2005 tentang guru dan dosen. Yang mengatur guru dan dosen bagaimana guru dan dosen diwajibkan untuk menguasai pembelajaran yang diampu, selalu mengembangkan diri serta harus memiliki sertifikat dalam mengajar.

\section{Kompetensi Profesional Guru}

Kompetensi Profesional guru merupakan kemampuan yang dimiliki oleh seorang guru dalam merencanakan serta melaksanakan proses pembelajaran dengan menguasai materi, konsep, pola pikir keilmuan yang mendukung mata pelajaran yang diampu serta terus mengembangkan diri untuk lebih baik dalam menjalankan profesi

9 Murni Yanto e Irwan Fathurrochman, «Manajemen Kebijakan Kepala Madrasah Dalam Meningkatkan Mutu Pendidikan», Jurnal Konseling Dan Pendidikan 7, n. 3 (2019): 125.

10 Muhammad Ali, Kebijakan Pendidikan Menengah dalam Perspektif Governance di Indonesia (Universitas Brawijaya Press, 2017), 40.

11 Anis Ali Mudlofir, «Korelasi Kebijakan Kepala Sekolah Dengan Kedisiplinan Dan Prestasi Belajar Siswa Kelas XI SMK Al-Islam Joresan Mlarak Ponorogo Tahun Pelajaran 2019/2020» (diploma, IAIN Ponorogo, 2021), 17, http://etheses.iainponorogo.ac.id/15042/. 
yang dia geluti (Wijaya, 2018, pag. 22). Berbicara tentang ciri-ciri guru Profesional Allport mengemukakan bahwa ciri-ciri orang yang mempunyai kepribadian matang di-antaranya. Pertama extension of the sense of self yaitu meningkatkan kesadaran diri dengan melihat sisi lebih dari sisi kekurangan. Kedua warm relatedness to other yaitu dapat membuat hubungan baik dengan orang lain. Ketiga self acceptance yaitu dapat mengontrol emosi dan mampu menjauhi sifat yang selalu berlebihan. Keempat realistic perception of reality yaitu memiliki pandangan yang realistis dalam kenyataan yang ada. Kelima self objectification yaitu dapat memahami diri sendiri. Keenam unifying of life yaitu memiliki pedomn hidup untuk menyatukan nilai-nilai yang kuat dalam ke-hidupan. ${ }^{12}$

Adapun faktor yang menentukan Profesionalisme seseorang menurut Sudarwan dalam bukunya ia mengutip pendapatnya Djojonegoro mengatakan bahwa ada ti-ga faktor yang menentukan Profesionalisme seseorang dalam suatu jabatan diantaranya. Pertama mempunyai keahlian yang khusus yang dipersiapkan oleh program Pendidikan keahlian. Kedua dapat memperbaiki serta mengembangkan keahlian yang ia miliki. Ketiga mendapatkan penghasilan yang sesuai dengan keahlian yang ia miliki. $^{13}$

Sudarman dalam bukunya ia mengutif pendapatnya Richard D. Kellough mengatakan bahwa guru yang Profesional harus beberapa kompetensi diantaranya. Pertama guru harus mampu menguasai pelajaran yang diampu. Kedua guru diharapkan mengikuti organisasi keguruan, mengikuti seminar, menambah wawasan dengan ban-yak membaca, banyak berdiskusi dengan sesama pengajar agar mampu membina peser-ta didik yang ia ajarkan. Ketiga guru harus mampu memahami bagaimana proses pem-belajaran dengan prosedur yang ada. Keempat guru sebagai fasilitator dalam proses pembelajar diharapkan mampu mengetahui dari mana mendapatkan pengetahuan tam-bahan. Kelima guru harus berperilaku yang baik agar dapat ditiru oleh peserta didik. Keenam berani mengambil resiko Ketika melakukan kesalahan dan bisa mencari solusi untuk menanggulanginya. Ketujuh guru tidak membedakan jenis kelamin peserta didik, akan tetapi ia memberi perilaku yang sama.

\footnotetext{
12 Muhamad Anwar, Menjadi Guru Profesional (Prenada Media, 2018), 16.

13 Sudarwan Danim, Profesionalisasi dan etika profesi guru, cetakan keempat (Bandung: Alfabeta,
} 2017), 5 
Kedelapan guru diharapkan dapat merencanakan serta dapat mengorganisasikan pelajaran dengan baik. Kesembilan guru harus mampu menjadi komunikator yang efektif. Kesepuluh guru dengan efektif da-lam pengambilan keputusan. Kesebelas. Guru harus konsisten dalam meningkatkan kemampuan mengajar. Kedua belas guru harus selalu memperhatikan keadaan peserta didik. Ketiga belas guru diharapkan selalu optimis dalam proses belajarnya para peser-ta didik dengan menyiapkan situasi belajar yang baik. Keempat belas guru menun-jukan sikap optimisme dalam kemampuan belajar siswa. Kelima belas guru harus adil dalam menentukan penelitian. Keenam belas guru harus konsisten memperhatikan pe-serta didik dalam Profesional dalam berbagai kesempatan. Ketujuh belas guru harus bekerja sama dengan wali murid serta selalu memelihara hubungan baik antara keduanya. Kedelapan belas guru memperlihatkan minat serta perhatian dalam berbagai hal. Kesembilan belas. Guru diharapkan mampu menciptakan humor yang baik. Kedua puluh guru harus cermat dalam melihat peserta didik yang membutuhkan bimbingan kedua puluh satu guru diharapkan mampu mengaitkan pembelajaran dengan kehidupan sehari-hari. Kedua puluh dua guru harus dapat dipercaya dalam membuat per-janjian ataupun kesepakatan. ${ }^{14}$

Hak dan kewajiban guru yang tercantum dalam undang-undang 14 tahun 2005 tentang guru dan dosen dinyatakan mempunyai hak diantaranya. Pertama memperoleh penghasilan di atas kebutuhan hidup minimal serta mendapatkan jaminan kesejahter-aan sosial. Kedua mendapatkan penghargaan atas prestasi yang ia raih. Ketiga mem-peroleh perlindungan dalam melaksanakan tugas dan ha katas intelektual yang ia miliki. Keempat mendapatkan kesempatan untuk menambah wawasan. Kelima mendapatkan serta dapat memanfaatkan sarana dan prasarana pembelajaran untuk menunjang tugas keprofesionalan. keenam memiliki kebebasan dalam memberikan penilaian serta ikut menentukan kelulusan, penghargaan dan hukum kepada peserta didik sesuai dengan apa yang ia perbuat. Ketujuh memperoleh rasa aman serta jaminan keselamatan dalam melakukan tugas. Kedelapan memiliki kebebasan untuk bergabung ke organisasi keguruan. Kesembilan mendapatkan kesempatan untuk berperan dalam menentukan kebijakan. Kesepuluh memperoleh

\footnotetext{
${ }^{14}$ Danim, 57-58.
} 
kesempatan untuk mengembangkan diri serta meningkatkan kualifikasi akademik yang ia miliki. Kesebelas mendapatkan pelatiha untuk mengembangan propesi. ${ }^{15}$

Kewajiban yang harus dijalankan sesuai dengan pasal 20 undang-undang nomor 14 tahun 2005 diantaranya. Pertama membuat perencanaan pembelajaran, melaksanakan pembelajaran serta mengevaluasi hasil dari pembelajaran. Kedua meningkatkan kemampuan akademik yang dimiliki sesuai dengan perkembangan zaman. Ketiga selalu bersikap adil tidak memandang gender, ras, suku dan lain sebagainya. Keempat menjunjung tinggi aturan yang ada sesuai dengan undang-undang, hukum, kode etik serta nilai-nilai agama yang ia anut. Kelima menjaga kesatuan dan persatuan bangsa. ${ }^{16}$

\section{METODE PENELITIAN}

Metode yang digunakan dalam penelitian ini adalah metode kualitatif, yaitu penelitian yang dilakukan secara deskriptif serta menganalisis fenomena, peristiwa, ak-tifitas social, sikap, kepercayaan maupun perspektif masing-masing orang maupun ke-lompok. ${ }^{17}$ Jenis penelitian ini adalah penelitian lapangan, yang dimana penelitian ini mendapatkan data atau informasi secara langsung di tempat penelitian. Penelitian ini dilakukan di MI NW Lendang Ara, Kec. Kopang Lombok Tengah yang dimana Kepala Madrasah dan Guru sebagai objek penelitian. Dalam pengolahan data peneliti menggunakan analisis deskriptif yaitu sebuah gaya analisis yang mempunyai tujuan sebagai penjelas suatu objek kajian berdasarkan penelitian ke lapangan agar mampu memaparkan sesuai dengan kondisi yang ada di lapangan. ${ }^{18}$ Penelitian ini menggunakan sistem wawancara dan observasi dalam pengumpulan data.

${ }^{15}$ Iwan Wijaya, Professional teacher: Menjadi Guru Profesional (Bandung: CV Jejak (Jejak Publisher), 2018), 42.

16 Wijaya, 43.

17 Nana Syaodih Sukmadinata, Metode penelitian pendidikan (Bandung: Program Pascasarjana Universitas Pendidikan Indonesia dengan PT Remaja Rosdakarya, 2017), 60.

18 Ali Baroroh, Trik-trik Analisis Statistik SPSS 15+CD (Jakarta: Elex Media Komputindo, 2008), 1. 


\section{HASIL PENELITIAN DAN PEMBAHASAN}

Kebijakan yang dilakukan oleh kepala MI NW Lendang ara dilandasi oleh UU nomor 14 tahun 2005 tentang guru dan dosen yang berbunyi:

"Guru dan dosen wajib memiliki kualifikasi akademik, kompetensi, sertifikat pendidik, sehat jasmani dan rohani, dan memenuhi kualifikasi lain yang dipersyaratkan satuan pendidikan tinggi tempat bertugas, serta memiliki kemampu-an untuk mewujudkan tujuan pendidikan nasional."

Menurut Bapak H. Zainal Hamdi, S.P.d.I. selaku kepala madrasah MI NW Lendang Ara.

Cara kami meningkatkan kompetensi profesional guru di MI NW Lendang Ara dengan memberikan berbagai macam pelatihan seperti seminar, supervisi dan lain sebagainya selanjutnya kami memberikan penghargaan bagi guru yang berprestasi, kami juga mengevaluasi guru apakah dalam pelaksanaan pembela-jaran sudah dijalankan dengan baik atau tidak. ${ }^{19}$

Dari hasil wawancara tersebut peneliti mengambil kesimpulan dalam meningkatkan kompetensi profesionalisme guru yang ada di MI NW Lendang Ara kepala madrasah membuat kebijakan diantaranya.

Pertama dalam membuat kurikulum sesuai dengan Keputusan Menteri Agama (KMA) nomor 183 tahun 2020 tentang rancangan kurikulum dengan menggunakan Kurikulum K13. Kebijakan yang dibuat oleh kepala madrasah secara tertulis dalam Keputusan Kepala Madrasah MI NW Lendang Ara tahun 2020 tentang guru MI NW Lendang Ara diwajibkan untuk membuat rencana pembelajaran, program semester, program tahunan, silabus, menganalisi kalender Pendidikan serta menentukan KKM masing-masing pelajaran sesuai dengan kurikulum K13.

Hal demikian sesuai dengan penelitian yang dilakukan Ali jufri ia mengatakan kepala madrasah berhak memberi kebijakan supaya guru membuat rencana pembelaja-ran, silabus, program semester serta program tahunan, untuk meningkatkan kompetensi profesional guru. ${ }^{20}$

\footnotetext{
${ }^{19}$ wawancara: Kepala Madrsah MI NW Lendang Ara, 18 juni 2021.

20 Pohan, «Kebijakan Kepala Madrasah Dalam Meningkatkan Profesional Guru», 89.
} 
Kedua kepala madrasah MI NW Lendang Ara mengadakan evaluasi setiap tiga bulan untuk mengetahui sampai mana kinerja guru dalam mengajar. Dalam hal ini kepala madrasah MI NW Lendang Ara dengan secara lisan memberikan kebijakan agar setiap tiga bulan semua guru diwajibkan untuk mengikuti evaluasi sampai mana kinerja yang telah dilaksanakan untuk mengetahui kompetensi profesionalisme guru dalam proses pembelajaran. Dalam penelitian yang dilakukan oleh Utomo ia mengatakan hal yang perlu dievaluasi dalam kinerja guru diantaranya persiapan dan perencanaan, pengelolaan kelas, proses pembelajaran serta tanggung jawab profesionalitas guru. ${ }^{21}$

Ketiga Kepala madrasah MI NW Lendang Ara mengadakan pembinaan untuk meningkat Profesionalitas guru dengan mengadakan supervisi, pelatihan keguruan, berdiskusi sesama guru serta mengadakan seminar multidisiplin keilmuan untuk menambah wawasan guru. Dalam hal ini Kepala madrasah MI NW Lendang Ara membuat kebijakan secara lisan untuk mengadakan supervisi dua kali dalam satu tahun serta memfasilitasi guru MI NW Lendang Ara dalam mengikuti seminar mapuan pelatihan keguruan baik yang dilakukan dalam madrasah maupun yang dilakukan di luar madrasah. Baharudin mengatakan dalam meningkatkan kompetensi profesional guru dengan mengadakan supervisi serta memberikan pelatihan-pelatihan keguruan agar kita mengetahui sampai mana kemampuan yang dimiliki oleh guru. ${ }^{22}$

Keempat kepala madrasah MI NW Lendang Ara memberikan kesejahteraan sesuai dengan jerih payah guru dalam mendidik peserta didik. Kebijakan ini tercantum dalam kebijakan kepala madrsah MI NW Lendang Ara tahun 2019 tentang guru diberikan upah sesuai dengan masa mengajarnya. Sudarman mengatakan dalam bukunya dari berbagai faktor yang mempengaruhi status guru, hal yang perlu diper-hatikan ialah upah terhadap guru hal demikian merupakan sebagai

21 Alexander Kismanto Utomo, Bambang Suteng Sulasmono, e Mawardi Mawardi, «Evaluasi Kinerja Guru Bersertifikasi», JMSP Jurnal Manajemen Dan Supervisi Pendidikan) 4, n. 1 (25 febbraio 2020): 60, https://doi.org/10.17977/um025v4i12019p052.

22 Baharuddin Baharuddin, «Kebijakan Kepala Madrasah Dalam Meningkatkan Kualitas Peserta Didik Dhuafa», al-fikerah: Jurnal Manajemen Pendidikan 8, n. 1 (22 luglio 2020): 2, https://doi.org/10.31958/jaf.v8i1.1787. 
penghormatan ter-hadap guru karena telah menyalurkan ilmu yang ia miliki kepada peserta didiknya. ${ }^{23}$

Kelima kepala madrasah MI NW Lendang Ara memberikan penghargaan terhadap guru yang berprestasi serta guru yang disiplin dalam mengajar untuk memotiva-si guru-guru yang lain agar terciptanya sistem Pendidikan yang bermutu. Kebijakan ini telah dirasakan oleh Ibu Fitriani selaku guru di MI NW Lendang Ara Ketika meraih juara lomba dalam ajang Tahfiz Qur'an tingkat kabupaten Lombok Tengah dalam hal ini kepala madrsah memberikan pengahargaan sebagai tanda apresiasi atas perestasi yang ia dapatkan. Hal demikian bertujuan untuk memotivasi guru yang lain agar bisa berprestasi.

Marjuni mengatakan memberikan penghargaan terhadap guru yang berprestasi bertujuan untuk menumbuhkan budaya saing yang sehat sesama guru, meningkatkan motivasi kompetensi serta kerja keras dan agar dapat membina kesadar untuk bisa mengebangkan diri. ${ }^{24}$

Keenam guru diharuskan untuk mengikuti organisasi keguruan KKG (kelompok kerja guru), MGMP (Musyawarah guru mata pelajaran). Kebijakan ini tercantum dalam keputusan Kepala Madrasah MI NW Lendang Ara tahun 2008 tentang guru MI NW lendang ara diwajibkan untuk mengikuti organisasi keguruan. Sugeng menyatakan keikutsertaan para guru dalam organisasi dapat meningkatkan kompetensi profesionalisme guru untuk lebih mengembangkan diri. ${ }^{25}$

Kebijakan yang telah dibuat oleh kepala madrasah MI NW Lendang Ara untuk meningkatkan kompetensi Profesionalisme guru MI NW Lendang Ara, dari hasil observasi yang peneliti dapatkan kebijakan tersebut telah diterapkan oleh guru-guru. Wa-laupun secara pelaksanaannya masih kurang optimal dengan adanya guru yang masih belum menguasai dalam menganalisis silabus seperti yang dituturkan oleh salah

${ }^{23}$ Danim, Profesionalisasi dan etika profesi guru, 91.

24 Andi Marjuni, «Penghargaan Profesi Guru Sebagai Agen Perubahan», Jurnal Inspiratif Pendidikan 9, n. 2 (31 dicembre 2020): 214, https://doi.org/10.24252/ip.v9i2.18341.

${ }_{25}$ Sugeng Prayoga e Safrida Yuniati, «Pengaruh Budaya Organisasi Sekolah Terhadap Kinerja Guru SMA Negeri Di Kota Mataram», Jurnal Kependidikan: Jurnal Hasil Penelitian Dan Kajian Kepustakaan Di Bidang Pendidikan, Pengajaran Dan Pembelajaran 5, n. 1 (10 marzo 2019): 58, https://doi.org/10.33394/jk.v5i1.1394. 
satu guru MI NW Lendang Ara. ${ }^{26}$ Kepala mad-rasah MI NW Lendang Ara juga selalu membuka diri untuk menampung kritikan maupun masukan dari guru-guru serta orang tua siswa untuk bahan evaluasi kebijakan yang ada untuk lebih baik lagi demi kemajuan MI NW Lendang Ara.

\section{KESIMPULAN}

Dari hasil penelitian ini kita mendapatkan kesimpulan bahwa dalam meningkatkan kompetensi profesional guru di MI NW Lendang Ara, dalam hal ini kepala madrasah MI NW Lendang Ara membuat kebijakan diantaranya pertama membuat kurikulum yang sesuai ketentuan yang ada dengan mewajibkan para guru untuk membuat Rencana pembelajaran, program semester, program tahunan. Kedua mengadakan supervisi, evaluasi kinerja guru, membuat pelatihan-pelatihan keguruan. Ketiga mem-berikan penghargaan bagi guru yang berprestasi. Keempat memberikan mensejahtera-kan guru sesuai dengan jerih payahnya dalam mengajar. Kelima memberikan penghar-gaan bagi guru yang berprestasi. Keenam mengarahkan guru untuk mengikuti organ-isasi keguruan seperti Kelompok kerja guru (KKG) serta Musyawarah guru mata pela-jaran (MGMP). Adapun efektifitas kebijakan yang dibuat oleh kepala madrasah MI NW Lendang Ara optimal, akan tetapi secara implementasinya belum sepenuhnya ter-laksana dengan baik. Kepala madrasah juga membuka diri bagi para guru maupun orang tua yang akan memberikan masukan dan kritikan demi kemajuan MI Lendang Ara.

\section{DAFTAR PUSTAKA}

Ali Baroroh. (2008). Trik-trik Analisis Statistik SPSS 15+CD. Jakarta: Elex Media Komputin-do.

Ali, M. (2017). Kebijakan Pendidikan Menengah dalam Perspektif Governance di Indonesia. Universitas Brawijaya Press.

Anwar, M. (2018). Menjadi Guru Profesional. Prenada Media.

Baharuddin, B. (2020). KEBIJAKAN KEPALA MADRASAH DALAM MENINGKAT-KAN KUALITAS PESERTA DIDIK DHUAFA. al-fikrah:

26 Hasil observasi pada tanggal 15 juni 2021. 
Jurnal Manajemen Pen-didikan, $\quad 8(1), \quad$ 1-10. https://doi.org/10.31958/jaf.v8i1.1787

Danim, S. (2017). Profesionalisasi dan etika profesi guru (cetakan keempat). Bandung: Alfabeta.

Departemen Pendidikan Nasional. (2007). Kamus Besar Bahasa Indonesia (Cetakan keem-pat). Jakarta: Balai Pustaka.

Fattah, N., \& Latifah, P. (2014). Analisis kebijakan pendidikan (cetakan keempat). Bandung: Remaja Rosdakarya.

Fauzi, I. (2019). Problematika Kebijakan Linierisasi dan Mutasi Guru di Kabupaten Jember. TARBIYATUNA, 12(1), 39-58. https://doi.org/10.36835/tarbiyatuna.v12i1.351

Kunandar. (2007). Guru profesional: Implementasi Kurikulum Tingkat Satuan Pendidikan (KTSP) dan persiapan menghadapi sertifikasi guru. Jakarta: RajaGrafindo Persada.

Marjuni, A. (2020). Penghargaan Profesi Guru Sebagai Agen Perubahan. Jurnal Inspiratif Pendidikan, 9(2), 208-217. https://doi.org/10.24252/ip.v9i2.18341

Mudlofir, A. A. (2021). Korelasi Kebijakan Kepala Sekolah dengan Kedisiplinan dan Prestasi Belajar Siswa Kelas XI SMK Al-Islam Joresan Mlarak Ponorogo Tahun Pelajaran 2019/2020 (Diploma, IAIN Ponorogo). IAIN Ponorogo. Recuperato da http:/ / etheses.iainponorogo.ac.id/15042/

Mufarohah, U. T. dan. (2018). Bunga Rampai Pendidikan (Formal, Non Formal, dan Infor-mal). Deepublish.

Pohan, A. J. (2020). Kebijakan Kepala Madrasah Dalam Meningkatkan Profesional Guru. AL-MAHYRA (Jurnal Penelitian Dan Pengembangan Keilmuan), 1(02), 78-95.

Prayoga, S., \& Yuniati, S. (2019). Pengaruh Budaya Organisasi Sekolah Terhadap Kinerja Guru SMA Negeri di Kota Mataram. Jurnal Kependidikan: Jurnal Hasil Penelitian Dan Kajian Kepustakaan Di Bidang Pendidikan, Pengajaran Dan Pembelajaran, 5(1), 54-60. https://doi.org/10.33394/jk.v5i1.1394

Purba, S., Revida, E., Tamrin, A. F., Bachtiar, E., Purba, B., Ramadhani, Y. R., ... Hidayatulloh, A. N. (2021). Analisis Kebijakan Pendidikan. Medan: Yayasan Kita Menulis.

Sukmadinata, N. S. (2017). Metode penelitian pendidikan. Bandung: Program Pascasarjana Universitas Pendidikan Indonesia dengan PT Remaja Rosdakarya.

Utomo, A. K., Sulasmono, B. S., \& Mawardi, M. (2020). Evaluasi Kinerja Guru Bersertifi-kasi. JMSP (Jurnal Manajemen Dan Supervisi Pendidikan), 4(1), 5264. https://doi.org/10.17977/um025v4i12019p052

Wijaya, I. (2018). Professional teacher: Menjadi Guru Profesional. Bandung: CV Jejak (Jejak Publisher).

Yanto, M., \& Fathurrochman, I. (2019). Manajemen kebijakan kepala madrasah dalam meningkatkan mutu pendidikan. Jurnal Konseling Dan Pendidikan, 7(3), 123-130. 